\title{
Cultivating the Interpersonal Domain: Compassion in the Supervisor-Doctoral Student Relationship
}

\author{
Oskar Lundgren ${ }^{1,2 *}$ and Walter Osika ${ }^{3,4}$ \\ ${ }^{1}$ Division of Children's and Women's Health, Crown Princess Victoria Children's Hospital, Linköping, Sweden, ²Department \\ of Biomedical and Clinical Sciences, Faculty of Medicine and Health Sciences, Linköping University, Linköping, Sweden, \\ ${ }^{3}$ Department of Neurobiology, Care Sciences and Society, Center for Social Sustainability, Karolinska Institute, Stockholm, \\ Sweden, ${ }^{4}$ Department of Clinical Neuroscience, Center for Psychiatry Research, Karolinska Institute \& Stockholm Health \\ Care Services, Stockholm, Sweden
}

OPEN ACCESS

Edited by:

James Kirby,

The University of Queensland,

Australia

Reviewed by:

Amy Louise Finlay-Jones, University of Western Australia, Australia

Alicia Carter,

The University of Queensland,

Australia

*Correspondence:

Oskar Lundgren

oskar.lundgren@liu.se

Specialty section:

This article was submitted to

Theoretical and Philosophical

Psychology,

a section of the journal

Frontiers in Psychology

Received: 30 May 2020

Accepted: 23 March 2021

Published: 30 April 2021

Citation:

Lundgren O and Osika W (2021)

Cultivating the Interpersonal Domain:

Compassion in the Supervisor-

Doctoral Student Relationship.

Front. Psychol. 12:567664.

doi: 10.3389/fpsyg.2021.567664
The long-term and complex supervisor-doctoral student relationship is often characterised by tension and frictions. In higher education research, models, and interventions that take the potential beneficial interpersonal effects of compassion into account seem to be scarce. Hence, the aim of this study was to conceptualise the potential role compassion could have in the cultivation of an affiliative and sustainable supervisor-doctoral student relationship. The concept of compassion was investigated and analysed in relation to a contemporary model of supervisor behaviours. Furthermore, a systematic literature search in the scientific databases PubMed, Psychlnfo, ScienceDirect, and Google Scholar was performed. The conceptual analysis revealed that the interpersonal domain, in which compassion could afford a shared sense of warmth, is neglected in previous definitions. Furthermore, the integration of compassion into a model of adaptive supervisor behaviour indicates a strong case for a salutary role for compassion in the supervisor-doctoral student relationship. However, the literature review showed that empirical data are lacking, and more studies are needed. The role of compassion deserves to be investigated empirically in this particular interpersonal context.

Keywords: doctoral student supervision, compassion, interpersonal relationship, conceptual paper, post graduate student

\section{INTRODUCTION}

\section{The Supervisor-Doctoral Student Relationship}

From the outside, doctoral studies might look like a dream come true for the lucky students who walk the academic path to a doctorate degree. What could be the downside of getting paid for reading, experimenting, thinking, and writing about a favourite subject, and then getting rewarded with a $\mathrm{PhD}$ title in the end? Well, it is actually possible to imagine that the 
long-term and complex relationship between students and their supervisors could turn into a source of friction. Indeed, research within the field of higher education show that relational pitfalls, disagreements, conflict, and other ethical issues are some of the main hindrances for progress with the academic work, and sometimes even contribute to mental health issues (Bergnéhr, 2013; Gunnarson et al., 2013; Moxham et al., 2013; Holbrook et al., 2014; Löfström and Pyhältö, 2014; Levecque et al., 2017; Corcelles et al., 2019). On the other hand, supervision experienced as supportive is associated with less emotional exhaustion among students (Devine and Hunter, 2017). From the supervisor's point of view, interpersonal difficulties are commonly experienced, although this facet of the relationship seems to be less well studied (Lindén, 1999).

As such difficulties are rather common, a variety of courses and development programmes for supervisors as preventive measures have been provided, and some also investigated (Lindén, 1999; Pearson and Brew, 2002). Among these, only a few have included the relational dimension of the supervisor role, and courses that use the latest tools and findings from clinical and social psychology seem to be rare (Lindén, 1999). One such example is a program developed by Manathunga (2005) called "Compassionate Rigour". However, the programme uses "compassion" as an umbrella term for being supportive in general and does not contain more specific aspects of compassion (Manathunga, 2005). Hence, findings from the recently sprouting literature on the influence of compassion on health and well-being (Gilbert, 2017; Seppelä et al., 2017; Kirby, 2017), and its potential to cultivate trust and cooperation in the workplace (Lilius et al., 2008), as well as to improve the classroom milieu in schools (Jazaieri, 2018) is not yet integrated into higher education curricula. This might reflect a substantial gap in knowledge.

\section{The Concept of Compassion}

The concept of compassion has played an essential role in diverse traditions such as Greek philosophy, Buddhist psychology, ethics, and contemporary moral philosophy (Fröding and Osika, 2015; Gilbert, 2017; Seppelä et al., 2017; White, 2017). Furthermore, the roots of compassion and its precursor empathy have been investigated and debated from evolutionary and biological perspectives (Gilbert, 2005; Keltner, 2009; De Waal, 2010; Goetz et al., 2010; Zaki and Cikara, 2015; Strauss et al., 2016; Klimecki, 2019; Kim et al., 2020).

Singer and Klimecki (2014) suggest that an empathic response to suffering can result in two kinds of reactions: empathic distress, which is also referred to as personal distress, and compassion, which they also referred to as empathic concern. Empathy refers to our general capacity to detect and resonate with others' emotional states irrespective of their valence. Empathic distress refers to a strong aversive and self-oriented response to others' suffering, accompanied by the desire to withdraw from an unpleasant situation to protect oneself from excessive negative feelings. On the other hand, compassion is conceived as an openness and connection to a feeling of concern for another person's suffering - also referred to as sympathy - accompanied by the motivation to help (Liotti and Gilbert, 2011). Consequently, it is associated with approach and prosocial motivations (Feldman and Kuyken, 2011; Singer and Klimecki, 2014; Gilbert et al., 2017). For our purpose, it is notable that the field of psychology has seen a surge in compassion research with theoretical, clinical, and educational facets (Strauss et al., 2016; Gilbert, 2017, 2020; Seppelä et al., 2017).

In clinical psychology, the ability to experience oneself as worthy of compassion, and mastering the interpersonal skills that enable one to act compassionately towards others, have become corner stones in novel therapeutic models, such as Compassion Focused Therapy (Gilbert, 2014, 2020). Grounded in evolutionary functional analysis, Gilbert (2019) has conceptualised compassion as sensitivity to suffering in self and others, with a commitment to try to alleviate and prevent it. In his simplified model of emotional regulation, he gives the compassionate mind a central role in dealing with both the restless achievement-focused part and the threat focused and safety-seeking part of the human mind (Gilbert, 2014). According to Gilbert (2014), compassion can generate affiliative experiences, which in turn generate courage to face and engage with difficult, even feared, emotions - including fear of compassion, which has been shown to be related to shame, self-criticism, and depression (Kirby et al., 2019). The academic milieu, in which the supervisor-doctoral student relationship is embedded, is well known for being competitive and hierarchical (Biron et al., 2008; Levecque et al., 2017). Thus, it is very likely that compassion could prevent the eroding effects of this context, perhaps by a jointly creating a safe base for the supervisor-student dyad to work from. Furthermore, in an interpersonal space characterised by trust and safety, supervisors and students may be less likely to act unethically and stay true to their values (Dutton et al., 2007; Ozawa-de Silva et al., 2012). Indeed, Gilbert (2014) argues that competencies that generate compassion towards self and others helps us function at our optimum.

The aim of this paper was thus to conceptualise the role of compassion in the supervisor-doctoral student relationship. In the remaining parts of this text, the word student will be used with a tacit limitation to a discussion of doctoral students.

\section{MATERIALS AND METHODS}

To conceptualise the role of compassion in the supervisorstudent relationship, we performed a stepwise inquiry of firstly; a search of the literature, secondly; an adaptation of a conceptual model of the supervisor-student relationship, thirdly; an expanded definition and description of the concept of compassion, and fourthly; an analysis of the application of compassion to the conceptual model of the supervisor-doctoral relationship. Lastly, implications for theoretical elaborations and future empirical investigations are discussed.

\section{Literature Search}

The first step of our inquiry into the role of compassion in the supervisor-doctoral student relationship was to perform a 
literature search. It was performed with systematic use of the following terms in the scientific databases Pubmed, PsychInfo, ScienceDirect, and Google scholar; "compassion and supervision" (+/- "doctoral student" and "PhD student") "compassion and supervisor and interpersonal relationship". This search resulted in no empirical articles on the subject. However, we found four references that commented on the topic, which was included as background and context for the analysis.

\section{The Supervisor-Student Relationship: A Conceptual Model}

There is evidence that supervisors' and doctoral students' interpersonal relationships have implications for the progress of the work and the satisfaction of the student (Moxham et al., 2013). In the literature of higher education research, there are several models that explicitly or implicitly take interpersonal aspects into account. For example, Gatfield (2005) investigated supervisor "styles" using the two dimensions of structure and support, and Lindén (1999) focused on more narrow factors of freedom vs. control.

For our purpose here, where the challenges and complexities of the relationship are of primary interest, it could be useful to consider the model of Mainhard et al. (2009), which uses a framework from teacher behaviours and evaluates degrees of behaviours on the two independent axes of influence and proximity. The two axes contain eight types of behaviours; leadership, helpfulness/friendliness, understanding, freedom/responsibility, uncertain, dissatisfied, admonishing, and strict (see Figure 1 below). The theoretical underpinnings of this model highlight that the supervisor-student relationship is characterised by bi-directional influences, and that the eight behavioural dimensions are dynamically interdependent. Some behaviours might provoke opposite behaviours, while others provoke similar, creating positive feedback loops. Thus, we view Maynard's model as a suitable vehicle for a further inquiry into how compassion and compassionate behaviours fit into this framework.

\section{Compassion: An Operational Definition}

One attempt to define compassion and operationalise it in the form of a practical intervention comes from Jazaieri et al. (2014). Compassion, according to the authors, is a multidimensional construct with four facets; (1) An awareness of suffering (in self or others) - a cognitive facet, (2) Sympathetic concern; being emotionally moved by suffering - an affective facet, (3) A wish to see the relief of the suffering - an intentional facet, and (4) A responsiveness or readiness to help relieve that suffering - a motivational facet. Other authors have presented a different order of the facets of compassion. Ozawa-de Silva et al. (2012), for example, placed the affective facet before the subsequent split of cognitive- and attentional facets. Initial studies of a compassion intervention developed by Jazaieri et al. (2014) have lent support to the hypothesis that training in compassion can influence both cognitive and emotional factors that support psychological flexibility and adaptive functioning.

The model from Jazaieri et al. (2014) represents the phenomenon of compassion in an individual, and it requires some extension to be fully applicable to the bi-directional interpersonal relationship between supervisor and student. Gilbert (2014) has argued that prosocial behaviours are sometimes neglected as an important goal for therapeutic change. In addition to overt expressions of compassion, the model also needs a facet that represent what the interaction does to the relationship and what is happening in the interpersonal space shared by supervisor and student. Thus, we suggest that the following two facets should be added for a complete model: (5) Displays of compassion, e.g., facial expressions and prosocial behaviours - a behavioural facet, and (6) A shared sense of warmth and trust - an experiential and relational facet Table 1.

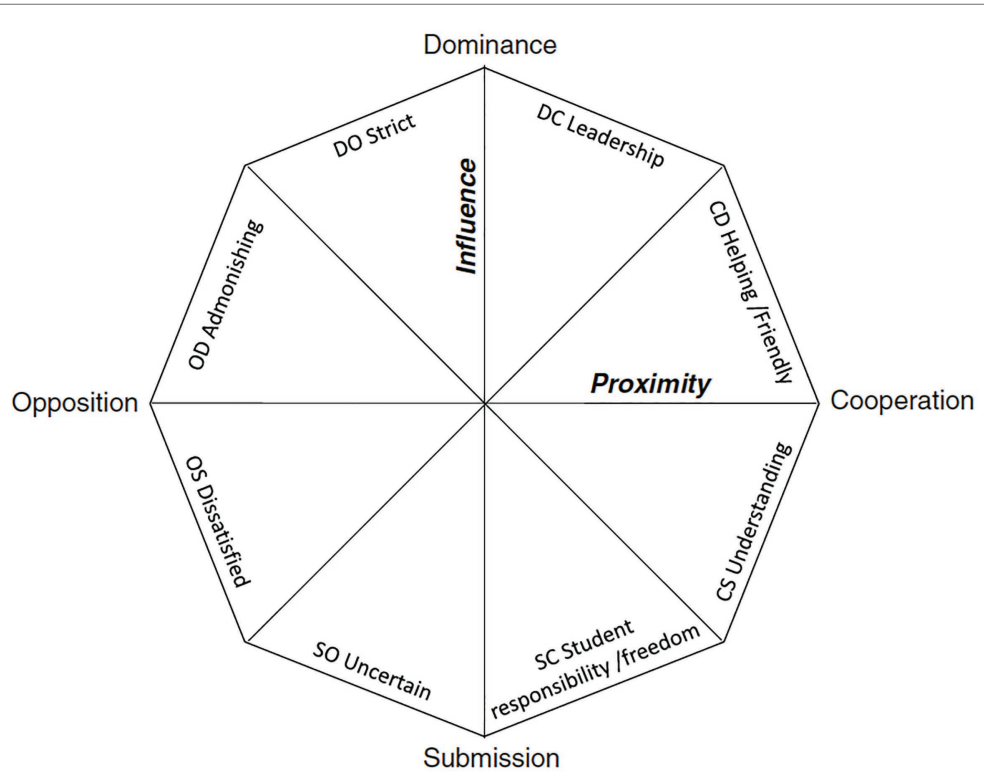

FIGURE 1 | Mainhard et al. (2009) model for supervisor interpersonal behaviour. 
TABLE 1 | Analysis: the application of compassion onto a model for supervisor interpersonal behaviour.

\section{Individual dimensions}

\section{(1) Awareness of suffering (cognitive)}

$\rightarrow$ Increased ability to recognise emotions and catch early warning signs of stress in self and student foster understanding (CS).

$\rightarrow$ More sensitive to the consequences of harsh or blunt negative feedback can prevent admonishing behaviours (OD).

(2) Sympathetic concern - being emotionally moved by suffering (affective) $\rightarrow$ More accurate empathetic assessment of student's needs and challenges could calibrate the inner compass for leadership style (DC).

$\rightarrow$ Modelling common humanity and being human could foster bi-directional understanding (CS).

$\rightarrow$ Precursor to signalling a caring attitude could facilitate trust (see also 6 below) and friendliness (CD).

(3) A wish to see the relief of the suffering (intentional) and (4) A responsiveness or readiness to help relieve that suffering (motivational)

$\rightarrow$ Motivating supportive and helping measures and directive leadership behaviours (CD, DC).

$\rightarrow$ Possibly a higher threshold for irritation over students' shortcomings, increased forgiveness, and less dissatisfied (DS).

$\rightarrow$ Prevention of maladaptive reactions against student distress could prevent a drift towards uncertain and dissatisfied behaviours (OS, SO).

\section{Interpersonal dimensions}

(5) Displays of compassion and overt compassionate behaviours (behavioural)

$\rightarrow$ Signalling a caring attitude could facilitate trust, which could catalyse processes related to creativity and productivity (CD).

$\rightarrow$ Create an atmosphere of security that could foster student creativity, productivity, and responsibility (SC).

$\rightarrow$ Inspiring (by model) students to develop self-compassion, which could foster self-leadership and responsibility (DC, SC).

(6) A shared sense of warmth and trust (experiential/relational) $\rightarrow$ Less depressive symptoms, anxiety, and mind wandering would increase supervisor and student stress resilience, improve friendliness and understanding (CD, CS), and possibly also decrease self/other strict criticism and dissatisfied behaviours (DO, OS).

The hypothesised cumulative positive changes in supervisor behaviours are visualised in Figure 2

\section{Compassion and the Supervisor-Student Relationship}

The literature search resulted in no empirical references, and only four articles with comments on the subject were deemed of interest for our analysis and discussion. One intriguing finding was the work of Manathunga (2005), mentioned in the introduction. The author presents a program for teaching supervisors called "compassionate rigour", that seeks to go beyond the administrative framing of supervision into the cognitive and pedagogical domain. However, Manathunga (2005) uses the term compassion as a synonym for support, encouragement, and empathy, and does not develop any theoretical framework for the implications of introducing compassion in this context.

A second result from the literature search was a recently published anthology called "The Pedagogy of Compassion at the Heart of Higher Education" (Gibbs, 2017). The book covers a wide variety of topics related to compassion and the challenges of contemporary academic life, including the cultivation of compassion in the classroom (Koutselini, 2017) and faculty leadership (Bresciani-Ludvik, 2017). However, none of the chapters address the topic of student-supervisor-relationship.

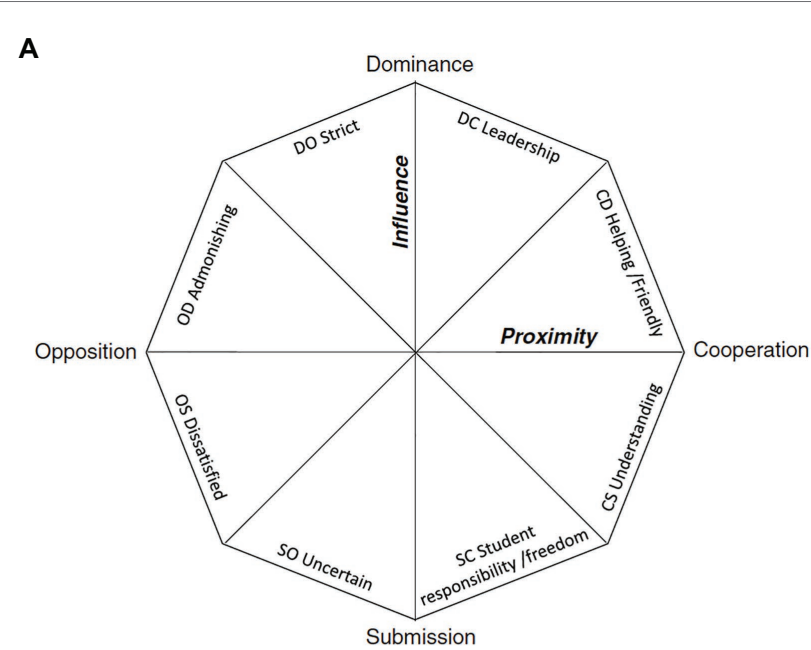

B

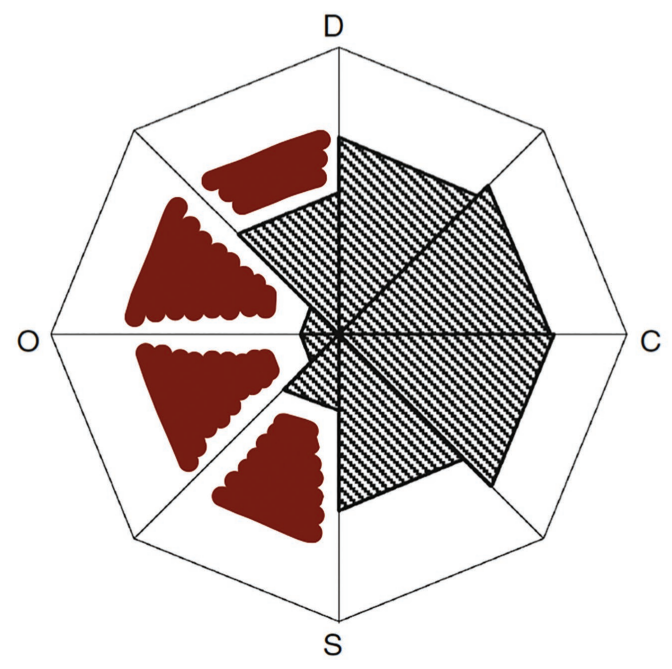

C

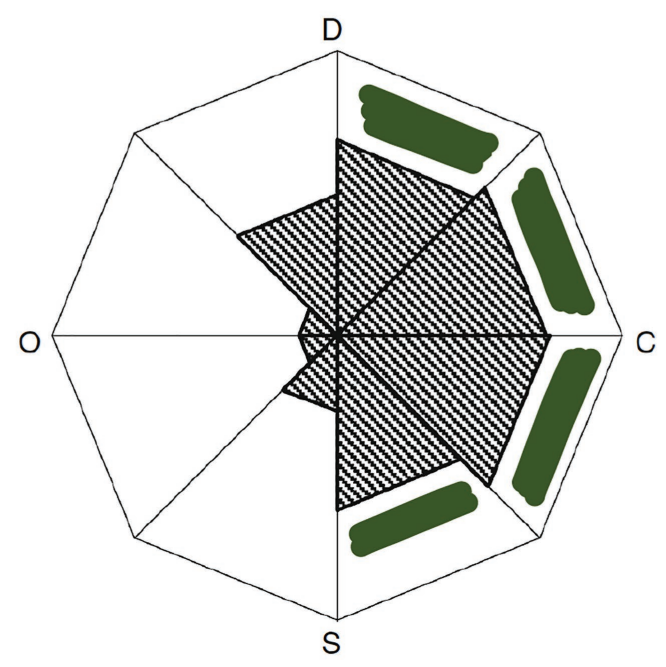

FIGURE 2 | (A) Mainhards model of supervisor behaviour. (B,C) Profiles of average supervisor behaviours in an earlier study (grey) and behaviours hypothetically linked to a lack of compassion (red) and behaviours that theoretically could be enhanced by compassion (green). Adapted from Mainhard et al. (2009). 
A fourth finding was an article termed "Postgraduate supervision: For better or worse", in which an experienced supervisor in the field of educational research critically elaborates about his changes in behaviours after a systematic and critical self-reflection (Olivier, 2007). The author identifies his directive values as compassion and commitment, although doubts his ability to live out these stated values. Furthermore, he is not convinced that his students subscribe to the same values and principles. Based on group-discussions with students and written reflections, Olivier (2007) found out that during meetings, both individual sessions, and group meetings, a positive relationship was forged. Based on these unsurprising observations and findings from the literature, Olivier (2007, p. 1138), provides a list of recommendations to fellow supervisors. His fourth advice; "A relationship characterised by mutual love, respect, and obligation should be developed to propagate a less 'top-down approach", validates our interest for the role of compassion in the supervision process. However, neither his observation nor his recommendation elucidates how the two processes are related and mutually influenced by each other. Overall, this limited outcome from the literature search indicates a knowledge gap regarding the role of compassion in the supervisor-doctoral student relationship and that empiric studies are very few or non-existent to date.

\section{The Potential of Compassion in the Supervisor-Student Relationship}

Here, we proceed with an analysis of the potential role of compassion in the supervisor-student relationship through a theoretical comparison of Mainhard's model with the extended Jazaieri (2018) definition of compassion. It could be of value to note that a supervisor with low capacity for compassion could not only fail to respond adaptively, he or she could also react with behaviours that are deleterious to the interpersonal relationship and increase the risk of ethical issues and even transgressions (Löfström and Pyhältö, 2014). Examples of such behaviours could be strict or admonishing behaviours, opposition or withdrawal of support, and an increase in submissive behaviours. Figure 2 shows the original Mainhard model and areas of unhelpful and helpful supervisor behaviours that might be influenced by compassion.

In addition to the theoretical basis of compassion as a pro-social phenomenon, that is generally considered a catalyst for closeness, cooperation, and well-being, our analysis includes recent evidence of compassion training's psychological effects. Interestingly, a review of this literature, which in many aspects is in its infancy, reveal that most studies to date are focused on outcome in the individual and very few report findings in the relational domains (Kirby, 2017; Condon, 2019; Condon et al., 2019; Klimecki, 2019). Considering the pro-social nature of compassion, it is somewhat surprising that the interpersonal domain seems to be understudied. For our purpose here, meaningful outcomes on the individual level represent the starting point, and informed reasoning is then used to bridge the knowledge gap of how these changes translate into the interpersonal space. The following positive and negative outcomes, summarised by Kirby (2017) are influenced by compassion interventions:

- Self-criticism and shame.

- Mind-wandering to unpleasant topics.

- Depressive symptoms and anxiety.

+ Readiness for health behaviour change.

+ Well-being and life satisfaction.

+ Ability to recognise emotions in others.

\section{DISCUSSION}

The objective of this paper was to conceptualise the phenomenon of compassion in the sometimes strained supervisor-doctoral student relationship. Overall, the literature review revealed that empirical data is largely missing regarding this specific context. We proceeded with our inquiry by analysing possible ways in which compassion could be used to improve supervision, using a theoretical framework based on teacher behaviour (Mainhard et al., 2009). The resulting conceptual framework provides theoretical support to the assumption that compassion may have significant positive impact on the supervisor-doctoral student relationship, both through increases in adaptive supervisor behaviours and decreases in maladaptive behaviours. Although Maynard's model does not include behaviours that are explicit examples of ethical issues in the relationship, e.g., admonitions, withdrawal of support, and strict behaviours could represent ethical trespasses in specific contexts. The model does also not include outright harmful behaviours such as insulting communication and sexual misconduct. However, since compassion is viewed as a pro-social process, it is plausible to suspect that supervisors with high levels of compassion would be less likely to engage in unethical behaviours (Ozawa-de Silva et al., 2012; Halperin, 2014; Fröding and Osika, 2015; Klimecki et al., 2016; DeSteno et al., 2018). Indeed, based on its central role in many systems of moral thought, and since compassion has been suggested to be an evolved and hardwired moral compass, it has recently been coined "the highest ethics" by researchers in the field of contemplative psychology (Kirby et al., 2017). Perhaps one of the major advantages of a focus on compassion in the supervisor role could be its potential to offer a guiding principle that could radically simplify an immensely complex responsibility.

The literature review revealed that the interpersonal space and relational experiences seem to represent understudied domains of outcome in compassion research. Recently, Gu et al. (2020) developed a tool for assessing compassion, and their definition of the construct overlaps with the extended Jazaieri et al. (2014) model used in our analysis. However, the sixth interpersonal dimension (a shared sense of warmth and trust) is not included in the definition or measurement of Gu et al. (2020), and perhaps this dimension needs its own measurement if we are to deepen our empirical understanding. When Gilbert (2014, 2019, 2020) developed Compassion Focused Therapy, he extended the definition of compassion beyond the individual level and described it as an integrated flow of compassion. In addition to compassion for others, this model also included becoming receptive to compassion, and compassion towards oneself. However, this model 
of the tri-directional flow of compassion neglects the interpersonal space domain, in which shared experiences of warmth, trust, and belonging are the fruits of an unimpeded flow of compassion.

Further research in this largely uncharted terrain may force scientist to confront philosophical and empirical questions stemming from different views of mind, consciousness, and by extension what constitutes and influence the shared interpersonal space (Varela et al., 2016; Jacobs, 2017; Andriopoulou and Prowse, 2020; Condon and Makransky, 2020). Taking a calculated risk of simplifying complex processes, we propose a model that visualises some crucial differences between western- and Buddhist views on the interpersonal space, which could stimulate future research and reasoning. While western psychology views the individual selves as building blocks in relationship models, a view grounded in Buddhist philosophy would consider the interpersonal space as a process that emerges from two interdependent and fluid selves, that co-arise partly from the interaction (Varela et al., 2016; Jacobs, 2017; Figure 3). Indeed, these differences could have extensive implications for how to conceptualise and measure interpersonal processes and the implications of more or less compassion in the shared space of an ongoing relationship.

One such conceptual challenge is the differences between Western dualism of separate processes of self- vs. other-focused compassion and Buddhist non-dual views, which have implications for both intervention design and choices of assessments in studies with interpersonal processes as outcomes (Quaglia et al., 2020). These philosophical issues might also provide challenges in the empirical investigation of sub-facets of social perception, appraisal, motivation, and action (e.g., emotion regulation), which relate to compassion (Ozawa-de Silva et al., 2012).

Distinctions between compassion and empathy are crucial to have in mind, but there are also lessons to be drawn from empathy research. Despite the limits of empathy (Västfäll et al., 2014; Bloom, 2017), decades of empirical work have shown a positive association between empathy and pro-social behaviour. In preparation for future studies, researchers should be aware of some of the risks and pitfalls that are often discussed in regard to empathy. One such caveat is that surplus empathy can lead to significant cognitive bias in situations with complex moral dimensions (Västfäll et al., 2014; Bloom, 2017; Cameron et al., 2019). Increased empathy could also lead to an increased risk of burnout as it might sensitise the individual to suffering without providing the ability to handle the emotional contagion (Singer and Klimecki, 2014). A second common critique is that too much closeness in this specific work relationship could become a burden that distracts from the central academic work (Hockey, 1995).

If researchers of higher education pedagogy would conduct intervention trials, perhaps by sending pairs of supervisors and students to compassion training seminars or retreats, they should consider measuring positive change and also register adverse events (Lindahl et al., 2017; Rozenthal et al., 2018). Future research should also investigate which contextual factors, at the team(including potential interpersonal challenges with co-supervisors) and management levels of an organisation, could represent obstacles for the growth of compassion in the student-supervisor relationship (Rupprecht et al., 2019). This perspective is highly relevant since the embrace of contemplative practices, such as mindfulness and compassion training programmes, has been criticised for focusing on individual psychological factors, while neglecting contextual factors such as organisational structure and culture (Purser et al., 2016). Indeed, one can assume that organisational factors in the hierarchical, strict, and sometimes penalising academic environment, including harsh competition for limited resources, could hamper supervisor's capacity for compassion (Biron et al., 2008;
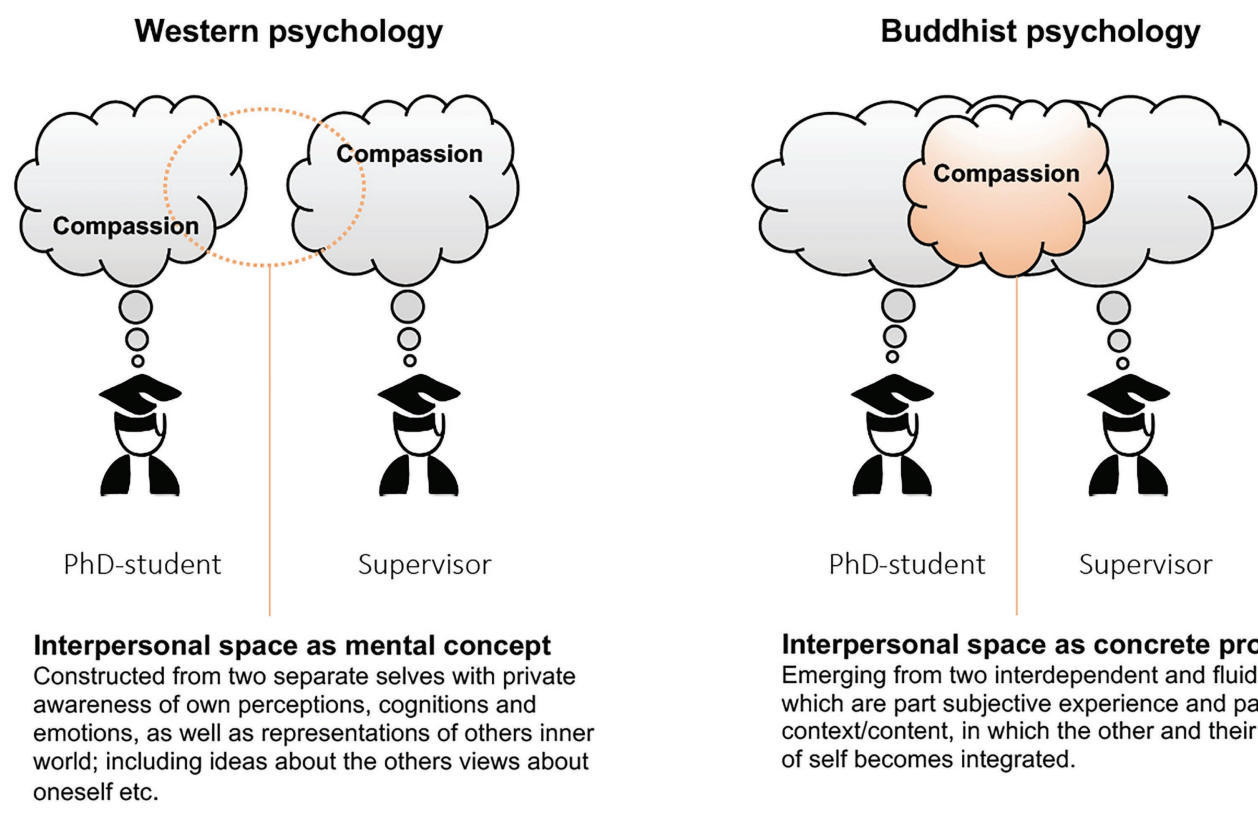

Interpersonal space as concrete process Emerging from two interdependent and fluid selves, which are part subjective experience and part context/content, in which the other and their sense of self becomes integrated.

FIGURE 3 | Western- and Buddhist views on the psychology of interpersonal space. Future measurements of e.g., a shared sense of warmth, as fruits of compassionate interactions, will have to address differing views of self and mind. 
Levecque et al., 2017). However, it also seems necessary to study individual differences and predisposing factors for the ability to generate a flow of compassion in the supervisor-student relationship, such as various blocks to compassion (Kirby et al., 2019) and early developed attachment patterns (Mikulincer and Shaver, 2005). Future research should also benefit from a sound scepticism of the current hype surrounding compassion interventions and other contemplative initiatives, and this could be attained by comparing interventions to other methods for cultivating resilience and prosocial functioning (Van Dam et al., 2017).

There are also instances where maladaptive motives and behaviour might simulate genuine compassion that should be studied in this hierarchal context. Catarino et al. (2014) described an important distinction between submissive compassion and genuine compassion, where the submissive kind can be explained as behaving in a helpful way, but where the intention solely is to prevent disruption of the connection to the other person or to be liked, and not from a compassionate motivation. Submissive compassion was associated with shame, depression, anxiety, and stress in the study by Catarino et al. (2014).

This conceptual article certainly raises more questions than it answers, which it is supposed to do. Among the most intriguing questions, that remain to be investigated, is whether supervisor's and student's compassion could be influenced through training and how beneficial changes in the relational domain translate into an improvement in student well-being and performance. Indeed, questions about how and what to measure as outcomes from compassion training in this context are of great importance.

\section{REFERENCES}

Andriopoulou, P., and Prowse, A. (2020). Towards an effective supervisory relationship in research degree supervision: insights from attachment theory. Teach. High. Educ. 25, 648-661. doi: 10.1080/13562517.2020.1731449

Bergnéhr, D. (2013). Att handleda en doktorand: en relationell balansgång som fordrar flexibilitet och struktur. Högre Utbildning 3, 173-185.

Biron, C., Brun, J. P., and Ivers, H. (2008). Extent and sources of occupational stress in university staff. Work 30, 511-522.

Bloom, P. (2017). Empathy and its discontent. Trends Cogn. Sci. 21, 24-31. doi: 10.1016/j.tics.2016.11.004

Bresciani-Ludvik, M. (2017). "Learning About Consequences, Community, Creativity and Courage: Cultivating Compassion in Higher Education Leadership," in The Pedagogy of Compassion at the Heart of Higher Education. ed. P. Gibbs (Cham: Springer Nature), 155-172.

Cameron, C. D., Hutcherson, C. A., Ferguson, A. M., Scheffer, J. A., Hadjiandreou, E., and Inzlicht, M. (2019). Empathy is hard work: people choose to avoid empathy because of its cognitive costs. J. Exp. Psychol. Gen. 148, 962-976. doi: 10.1037/xge0000595

Catarino, F., Gilbert, P., McEwan, K., and Baião, R. (2014). Compassion motivations: distinguishing submissive compassion from genuine compassion and its association with shame, submissive behavior, depression, anxiety and stress. J. Soc. Clin. Psychol. 33, 399-412. doi: 10.1521/jscp.2014.33. 5.399

Condon, P. (2019). Meditation in context: factors that facilitate prosocial behavior. Curr. Opin. Psychol. 28, 15-19. doi: 10.1016/j.copsyc.2018.09.011

Condon, P., Dunne, J., and Wilson-Mendenhall, C. (2019). Wisdom and compassion: a new perspective on the science of relationships. J. Moral Educ. 48, 98-108. doi: 10.1080/03057240.2018.1439828

Condon, P., and Makransky, J. (2020). Recovering the relational starting point of compassion training: a foundation for sustainable and inclusive care. Perspect. Psychol. Sci. 15, 1346-1362. doi: 10.1177/1745691620922200
Perhaps both supervisors and students experience of engagement and sense of meaning should be included.

Interestingly, Whitelock et al. (2008) have shown that a positive interpersonal climate was experienced as one of the chief factors to foster creativity among students and supervisors. Perhaps, in the downstream currents of increased compassion, supervisors and students could find themselves becoming more inventive and original in their thinking and writing.

\section{AUTHOR CONTRIBUTIONS}

OL conceived the presented idea, including theoretical background regarding supervisor behaviour and performed the systematic literature search. OL and WO provided input on the role of compassion in supervisor-doctorate student relationship, and contributed to the analysis of the results and writing of the manuscript. All authors contributed to the article and approved the submitted version.

\section{ACKNOWLEDGMENTS}

We would like to thank our supervisors and doctoral students for providing insights regarding the supervisors-doctoral student relationship, as well as forerunners in the contemplative and compassion sciences that have inspired us to pursue this study.

Corcelles, M., Cano, M., Liesa, E., Gonnzáles-Ocampo, G., and Castelló, M. (2019). Positive and negative experiences related to doctoral study conditions. High. Educ. Res. Dev. 38, 922-939. doi: 10.1080/07294360.2019.1602596

De Waal, F. (2010). The Age of Empathy: Nature's Lessons for a Kinder Society. New York: Broadway Books.

DeSteno, D., Lim, D., Duong, F., and Condon, P. (2018). Meditation inhibits aggressive responses to provocations. Mindfulness 9, 1117-1122. doi: 10.1007/s12671-017-0847-2

Devine, K., and Hunter, K. H. (2017). PhD student emotional exhaustion: the role of supportive supervision and self-presentation behaviours. Innov. Educ. Teach. Int. 54, 335-344. doi: 10.1080/14703297.2016.1174143

Dutton, J. E., Lilius, J., and Kano, J. (2007). "The Transformative Potential of Compassion at Work," in Handbook of Transformative Cooperation: New Designs and Dynamics. ed. S. K. Piderit (Stanford: Stanford University Press), 107-126.

Feldman, C., and Kuyken, W. (2011). Compassion in the landscape of suffering. Cont. Buddhism 12, 143-155. doi: 10.1080/14639947.2011.564831

Fröding, B., and Osika, W. (2015). Neuroenhancement: How Mental Training and Meditation Can Promote Epistemic Virtue. New York: Springer International Publishing.

Gatfield, T. (2005). An investigation info PhD supervisory management styles: development of a dynamic conceptual model and its managerial implications. J. High. Educ. Policy Manag. 27, 311-325. doi: 10.1080/13600800500283585 Gibbs, P. (2017). The Pedagogy of Compassion at the Heart of Higher Education. Cham: Springer Nature.

Gilbert, P. (ed.) (2005). “Compassion and Cruelty: a Biopsychosocial Approach”, in Compassion: Conceptualisations, Research and Use in Psychotherapy. New York: Routledge.

Gilbert, P. (2014). The origin and nature of compassion focused therapy. Br. J. Clin. Psychol. 53, 6-41. doi: 10.1111/bjc.12043

Gilbert, P. (ed.) (2017). Compassion: Concepts Research and Applications. New York: Routledge.

Gilbert, P. (2019). Explorations into the nature and function of compassion. Curr. Opin. Psychol. 28, 108-114. doi: 10.1016/j.copsyc.2018.12.002

Gilbert, P. (2020). Compassion: from its evolution to a psychotherapy. Front. Psychol. 11:586161. doi: 10.3389/fpsyg.2020.586161 
Gilbert, P., Catarino, F., Duarte, C., Matos, M., Kolts, R., Stubbs, J., et al. (2017). The development of compassionate engagement and action scales for self and others. J. Compass. Health Care 4, 1-24. doi: 10.1186/s40639-017-0033-3

Goetz, J. L., Keltner, D., and Simon-Thomas, E. (2010). Compassion: an evolutionary analysis and empirical review. Psychol. Bull. 136, 351-374. doi: 10.1037/a0018807

Gu, J., Baer, R., Cavanagh, K., Kuyken, W., and Strauss, C. (2020). Development and psychometric properties of the Sussex-Oxford compassion scales (SOCS). Assessment 27, 3-20. doi: 10.1177/1073191119860911

Gunnarson, R., Jonasson, G., and Billhult, A. (2013). The experience of disagreement between student and supervisors in $\mathrm{PhD}$ education: a qualitative study. BMC Med. Educ. 13:134. doi: 10.1186/1472-6920-13-134

Halperin, E. (2014). Emotion, emotion regulation, and conflict resolution. Emot. Rev. 6, 68-76. doi: 10.1177/1754073913491844

Hockey, J. (1995). Getting too close: a problem and possible solution in social science PhD supervision. Br. J. Guid. Couns. 23, 199-210. doi: 10.1080/03069889508253005

Holbrook, A., Shaw, K., Scevak, J., Bourke, S., Cantwell, R., and Budd, J. (2014). PhD candidate expectations: exploring mismatch with experience. Int. J. Doct. Stud. 9, 329-346. doi: 10.28945/2078

Jacobs, B. (2017). The Original Buddhist Psychology: What the Abhidharma Tells Us About How We Think, Feel and Experience Life. Berkley, California: North Atlantic Books.

Jazaieri, H. (2018). Compassionate education from pre-school to graduate school: bringing a culture of compassion into the classroom. J. Res. Innov. Teach. Learn. 11, 22-66. doi: 10.1108/JRIT-08-2017-0017

Jazaieri, H., McGonigal, K., Jinpa, T., Doty, J. R., Gross, J. J., and Goldin, P. R. (2014). A randomized controlled trial of compassion cultivation training: effects on mindfulness, affect and emotion regulation. Motiv. Emot. 38, 23-25. doi: 10.1007/s11031-013-9368-z

Keltner, D. (2009). Born to Be Good: The Science of a Meaningful Life. New York: WW Norton \& Company.

Kim, J. J., Parker, S. L., Doty, J. R., Cunnington, R., Gilbert, P., and Kirby, J. N. (2020). Neurophysiological and behavioural markers of compassion. Sci. Rep. 10:6789. doi: 10.1038/s41598-020-63846-3

Kirby, J. N. (2017). Compassion interventions: the programmes, the evidence, and implications for research and practice. Psychol. Psychother. 90, 432-455. doi: $10.1111 /$ papt.12104

Kirby, J. N., Day, J., and Sagar, V. (2019). The 'flow' of compassion: a metaanalysis of the fears of compassion svales and psychological functioning. Clin. Psychol. Rev. 70, 26-39. doi: 10.1016/j.cpr.2019.03.001

Kirby, J. N., Steindl, S. R., and Doty, J. M. (2017). "Compassion as the Highest Ethics," in Practitioner's Guide to Ethics and Mindfulness-Based Interventions. ed. L. M. Monteiro (Cham: Springer International Publishing), 253-275.

Klimecki, O. M. (2019). The role of empathy and compassion in conflict resolution. Emot. Rev. 11, 310-325. doi: 10.1177/1754073919838609

Klimecki, O. M., Mayer, S. V., Jusyte, A., Scheeff, J., and Schönenberg, M. (2016). Empathy promotes altruistic behavior in economic interactions. Sci. Rep. 6:31961. doi: 10.1038/srep31961

Koutselini, M. (2017). “The Reflective Paradigm in Higher Education and Research: Compassion in Communities of Learning" in The Pedagogy of Compassion at the Heart of Higher Education. ed. P. Gibbs (Cham: Springer Nature), 203-212.

Levecque, K., Anseel, F., De Beuckelaer, A., Van der Heyden, J., and Gisle, L. (2017). Work organization and mental health problems in $\mathrm{PhD}$ students. Res. Policy 46, 868-879. doi: 10.1016/j.respol.2017.02.008

Lilius, J. M., Worline, M. C., Maitlis, S., Kanov, J., Dutton, J. E., and Frost, P. (2008). The contours and consequences of compassion at work. J. Organ. Behav. 29, 193-218. doi: 10.1002/job.508

Lindahl, J. R., Fisher, N. E., Cooper, D. J., Rosen, R. K., and Britton, W. B. (2017). The varieties of contemplative experience: a mixed methods study of meditations-related challenges in Western Buddhists. PLoS One 12:e176239. doi: 10.1371/journal.pone.0176239

Lindén, J. (1999). The contribution of narrative to the process of supervising PhD-students. Stud. High. Educ. 24, 351-369. doi: 10.1080/0307507991233 1379945

Liotti, G., and Gilbert, P. (2011). Mentalizing, motivation, and social mentalities: theoretical considerations and implications for psychotherapy. Psychol. Psychother. 84, 9-25. doi: 10.1348/147608310X520094

Löfström, E., and Pyhältö, K. (2014). Ethical issues in doctoral supervision: the perspectives of $\mathrm{PhD}$-students in the natural and behavioural sciences. Ethics Behav. 24, 195-214. doi: 10.1080/10508422.2013.830574
Mainhard, T., van der Rijst, R., and van Tartwijk, J. (2009). A model for the supervisor-doctoral student relationship. High. Educ. 58, 359-373. doi: 10.1007/ s10734-009-9199-8

Manathunga, C. (2005). The development of research supervision: "turning the light on a private space”. Int. J. Acad. Dev. 10, 17-30. doi: 10.1080/136014 40500099977

Mikulincer, M., and Shaver, P. R. (2005). Attachment security, compassion, and altruism. Curr. Dir. Psychol. Sci. 14, 34-38. doi: 10.1111/j.09637214.2005.00330.x

Moxham, L., Dwyer, T., and Reid-Searl, K. (2013). Articulating expectations for $\mathrm{PhD}$ candidature upon commencement: ensuring supervision/student 'best fit'. J. High. Educ. Policy Manag. 35, 345-354. doi: 10.1080/1360080X. 2013.812030

Olivier, M. A. J. (2007). Postgraduate supervision: for better or worse? South Afr. J. High. Educ. 21, 1126-1141. doi: 10.4314/sajhe.v21i8.25765

Ozawa-de Silva, B. R., Dodson-Lavelle, B., Raison, C. L., and Negi, L. T. (2012). Compassion and ethics: scientific and practical approaches to the cultivation of compassion as a foundation for ethical subjectivity and well-being. J. Healthcare Sci. Hum. 2, 145-161.

Pearson, M., and Brew, A. (2002). Research training and supervision development. Stud. High. Educ. 27, 135-150. doi: 10.1080/03075070220119986c

Purser, R. E., Forbes, D., and Burke, A. (2016). Handbook of Mindfulness: Culture, Context and Social Engagement. Switzerland: Springer International Publishing.

Quaglia, J. T., Soisson, A., and Simmer-Brown, J. (2020). Compassion for self versus other: a critical review of compassion training. J. Posit. Psychol. 1-16. doi: 10.1080/17439760.2020.1805502

Rozenthal, A., Costanguayu, L., Dimidjan, S., Lambert, M., Shafran, R., Andersson, G., et al. (2018). Negative effects in psychotherapy: commentary and recommendations for future research and clinical practice. BJPsych. Open 4, 307-312. doi: 10.1192/bjo.2018.42

Rupprecht, S., Koole, W., Chskalson, M., Tamdjidi, C., and West, M. (2019). Running too far ahead? Towards a broader understanding of mindfulness in organisations. Curr. Opin. Psychol. 28, 32-36. doi: 10.1016/j.copsyc.2018.10.007

Seppelä, E. M., Simon-Thomas, E., Brown, S. L., Worline, M. C., Cameron, M. C., and Doty, J. R. (eds.) (2017). The Oxford Handbook of Compassion Science. Oxford: Oxford University Press.

Singer, T., and Klimecki, O. M. (2014). Empathy and compassion. Curr. Biol. 24, R875-R878. doi: 10.1016/j.cub.2014.06.054

Strauss, C., Taylor, B. L., Gu, J., Kuyken, W., Baer, R., Jones, F., et al. (2016). What is compassion and how can we measure it? A review of definitions and measures. Clin. Psychol. Rev. 47, 15-27. doi: 10.1016/j.cpr.2016.05.004

Van Dam, N. T., van Vugt, M. K., Vago, D. R., Schmalzl, L., Saron, C., Olendsky, A., et al. (2017). Mind the hype: a critical evaluation and prescriptive agenda for research on mindfulness and meditation. Perspect. Psychol. Sci. 13, 36-61. doi: 10.1177/1745691617709589

Varela, F. J., Thompson, E., and Rosch, E. (2016). The Embodied Mind: Cognitive Science and Human Experience. 2nd Edn. Cambridge MA: MIT press.

Västffäll, D., Slovic, P., Mayorga, M., and Peters, E. (2014). Compassion fade: affect and charity are greatest for a single child in need. PLoS One 9:e100115. doi: 10.1371/journal.pone.0100115

White, R. (2017). "Compassion in Philosophy and Education," in The Pedagogy of Compassion at the Heart of Higher Education. ed. P. Gibbs (Cham: Springer Nature), 19-31.

Whitelock, D., Faulkner, D., and Miell, D. (2008). Promoting creativity in PhD supervision: tension and dilemmas. Think. Skills Creat. 3, 143-153. doi: 10.1016/j.tsc.2008.04.001

Zaki, J., and Cikara, M. (2015). Addressing empathic failures. Curr. Dir. Psychol. Sci. 24, 471-476. doi: 10.1177/0963721415599978

Conflict of Interest: The authors declare that the research was conducted in the absence of any commercial or financial relationships that could be construed as a potential conflict of interest.

Copyright (c) 2021 Lundgren and Osika. This is an open-access article distributed under the terms of the Creative Commons Attribution License (CC BY). The use, distribution or reproduction in other forums is permitted, provided the original author(s) and the copyright owner(s) are credited and that the original publication in this journal is cited, in accordance with accepted academic practice. No use, distribution or reproduction is permitted which does not comply with these terms. 